$1-19-2021$

\title{
Patient Recommendations for Providers to Avoid Stigmatizing Weight in Rural-Based Women With Low Income
}

\author{
Declan Watson \\ Katherine Hughes \\ Emma Robinson \\ Jacqueline Billette \\ Andrea E. Bombak
}

Follow this and additional works at: https://aah.org/jpcrr

Part of the Community Health and Preventive Medicine Commons, Family Medicine Commons, Health Services Research Commons, Primary Care Commons, Public Health Education and Promotion

Commons, and the Women's Health Commons

\section{Recommended Citation}

Watson D, Hughes K, Robinson E, Billette J, Bombak AE. Patient recommendations for providers to avoid stigmatizing weight in rural-based women with low income. J Patient Cent Res Rev. 2021;8:20-30. doi:

10.17294/2330-0698.1752

Published quarterly by Midwest-based health system Advocate Aurora Health and indexed in PubMed Central, the Journal of Patient-Centered Research and Reviews (JPCRR) is an open access, peer-reviewed medical journal focused on disseminating scholarly works devoted to improving patient-centered care practices, health outcomes, and the patient experience. 


\title{
Patient Recommendations for Providers to Avoid Stigmatizing Weight in Rural-Based Women With Low Income
}

\author{
Declan Watson, BA, ${ }^{1}$ Katherine Hughes, $\mathrm{MPH},{ }^{2}$ Emma Robinson, $\mathrm{BA},{ }^{3}$ Jacqueline Billette, MA, MPH, ${ }^{2}$ \\ Andrea E. Bombak, $\mathrm{PhD}^{3}$ \\ ${ }^{1}$ Department of Psychology, University of New Brunswick, Fredericton, Canada; ${ }^{2}$ School of Health Sciences, Central \\ Michigan University, Mount Pleasant, MI; ${ }^{3}$ Department of Sociology, University of New Brunswick, Fredericton, Canada
}

Purpose Weight stigma has become widespread within health care and disproportionately affects women,
who are under greater appearance-based scrutiny than men. It is also well established that rural-
based individuals with low incomes suffer greater health disparities compared with urban, higher-income
counterparts, yet studies examining recommendations for nonstigmatizing health care among higher-
weight women from low-income rural settings are lacking. This study examined the experiences and
recommendations of higher-weight, low-income, rural women, with the aim of improving health care for
similar populations.

Methods In-depth, semi-structured interviews were conducted in a rural region of the Midwestern United States to explore participants' recommendations for redressing stigma within health care. All participants $(n=25)$ self-identified as higher-weight, low-income, rural women.

Results $\quad$ All participants experienced or were aware of weight stigma within health care. Themes identified from responses were understanding patients and their situations, offering options and supplemental information, communicating effectively, taking time, and having a positive attitude. Patient recommendations focused on correcting physician biases, rapport-building, and providing holistic care.

Conclusions The findings suggest that weight stigma is prevalent within health care provided to low-income women in rural U.S. Midwest and that there are specific communication and training approaches that may reduce the prevalence of weight stigma in health care. (J Patient Cent Res Rev. 2021;8:20-30.)

Keywords $\quad$ weight stigma; weight bias; rural; health care; low income; disparities

\section{Weight Stigma}

Weight stigma, or weight bias, refers to negative attitudes and beliefs based on a person's weight or size, which often present as stereotyping, prejudice, and rejection. ${ }^{1}$ Weightbased discrimination is highly prevalent; for women, it occurs at rates roughly equivalent to racial discrimination. ${ }^{2}$ When women do not meet societal expectations of appearance, they become subject to weight stigma and marginalization. ${ }^{3}$ Women are more likely to internalize their experiences of weight stigma than men. ${ }^{4}$

Within health care, a weight-normative approach is dominant. Health care providers (HCPs) focus on

Corresponding author: Andrea E. Bombak, PhD, University of New Brunswick, PO Box 4400, Fredericton, Canada E3B 5A3 (andrea.bombak@unb.ca) weight measurement (especially body mass index $[\mathrm{BMI}])$ as a primary health indicator and weight loss as the mechanism to "restore" health. ${ }^{5}$ Indeed, physicians may treat weight as a "master status" overriding other potential explanations for patients' symptoms, preventing physicians from performing additional diagnostic tests or prescribing certain treatments beyond recommending weight loss. ${ }^{5-8}$

Previous research has found that HCPs endorse many stereotypes about higher-weight patients, ${ }^{7,9}$ assuming higher weight to be unhealthy and indicative of negative personal characteristics such as laziness and lack of discipline. ${ }^{3,7,9,10}$ Such stereotypes discount more complex and nuanced findings. ${ }^{11}$ In a study by $\mathrm{Hebl}$ and $\mathrm{Xu},{ }^{12}$ physicians reported spending less time with higher-weight patients than with lower-weight patients, reported more negative appraisals of patients as their weight increased, and reported being more likely to view appointments 
with higher-weight patients as a waste of time. Women of higher weight may therefore systematically avoid situations, like health care settings, where their weight is seen as problematic. ${ }^{13}$

Indeed, research shows that BMI is positively correlated with delaying or avoiding care. ${ }^{14}$ Mensinger and colleagues $^{15}$ found that, among women, experiencing weight stigma was associated with increased body-related shame, which was associated with higher stress around accessing health care and, subsequently, with health care avoidance. The expectation of poor treatment may cause stress and avoidance of care; women may fear that HCPs hold negative biases and will scold them because of their weight. ${ }^{7,14}$ This paper responds to a call for greater qualitative research on patients' stigma experiences, greater inclusion of higher-weight patients' insights into care preferences, and the need for an intersectional lens in addressing stigma. ${ }^{4,16}$

\section{Significance of the Population: Rurality and Low Income}

Diverse populations coping with multiple disadvantages are underexplored in weight stigma research. ${ }^{4}$ People living in rural areas with lower incomes face increased barriers accessing and receiving health care. ${ }^{17}$ For rural individuals with physical disabilities in particular, lack of public transportation and specialized services present major barriers to accessing care. ${ }^{18}$

Rural women experience greater poverty and marginalization compared to rural men, which contributes to women's lower health status. ${ }^{19}$ Rural residents report a higher ratio of out-of-pocket health care expenditures compared to their urban counterparts, ${ }^{20}$ and they are more likely to spend more than $10 \%$ of their annual income on health care. ${ }^{20}$ Unfortunately, a simplistic weightcentric approach to health may not consider how social, cultural, and material factors, such as rurality and income, contribute to the health and lifestyle of patients. ${ }^{3,5}$

The geographic components of navigating larger body sizes is an overlooked component of weight stigma research. ${ }^{21}$ While focusing on metropolitan Arizona, for example, Schuster and colleagues found that larger size among women affected neighborhood engagement. ${ }^{22}$ However, American rural and urban preoperative weight loss surgery patients did not differ in their (frequently high) ratings of internalized weight bias, which was associated with depressive symptoms preoperatively and reduced weight loss after surgery. ${ }^{23}$ Likewise, among students in nursing, social work, and education at a university in the U.S. Northeast, location of residence (suburban, urban, or rural) did not affect weight-based attitudes..$^{24}$ Nonetheless, rurality remains an important component to consider when addressing weight issues. Rural places have developed a pejorative "backward," "obesogenic" reputation. ${ }^{25}$ Studies into rural culture have revealed distinctions relevant to health and embodiment, including the reliance on independence and religion, a focus on capacity to work and not burdening others, a fear of stigma and disclosure, and a distrust in health care. ${ }^{26-30}$ Therefore, rurality may materially and socially shape individuals' health care experiences, behaviors, and social treatment.

Furthermore, the relationship between weight stigma and income or educational attainment is understudied, and available research does not provide consistent evidence. ${ }^{31}$ American women may feel less financially satisfied than men with their medical care, perhaps due to lower income. ${ }^{32}$ While research has tended to focus on how being at a lower income may precede weight gain, importantly, through discriminatory processes, being at a higher weight may affect income (particularly for women) in the United States. ${ }^{33}$ Higher-weight women consistently earn less than lower-weight women, ${ }^{34}$ whereas higher-weight men eventually make equivalent earnings compared to lower-weight men. Education and marriage prospects, both linked to women's socioeconomic status, also may be affected by weight status among women. ${ }^{34}$

The insights of higher-weight individuals should be incorporated into weight-based research. ${ }^{16}$ Weight stigma negatively affects health and can even lead to indicators associated with early death such as elevated blood pressure and heart disease. ${ }^{35}$ Published recommendations note that HCPs are often not trained on weight management in school ${ }^{36}$ and that physicians often feel like they lack knowledge, confidence, and skills to properly manage higher-weight patients. ${ }^{37}$ Even mental health providers rarely receive training on how to talk and work with higher-weight individuals. ${ }^{38}$ Past reports have called for HCPs to receive more training to reduce stigma and communicate sensitively, ${ }^{35,36,39}$ noting a need to obtain higher-weight patients' insight into preferred communication. ${ }^{35}$

\section{Intersectionality}

An intersectional approach recognizes that individuals may be members of numerous disadvantaged groups, resulting in a multiplicative effect on the disadvantages they encounter. ${ }^{40,41}$ Experiencing multiple disadvantages can increase the likelihood of experiencing discrimination and worse health outcomes compared to singly disadvantaged individuals or those from privileged social groups. ${ }^{42}$ One American intersectional weight study found that lower-income participants reported 
higher levels of weight stigma, with participants' responses to weight stigma, such as internalization and coping strategies, differing along the lines of race and gender. ${ }^{4}$ Failure to consider intersectionality can produce a distorted image of participants' attempts to navigate health care.

Recommendations from diverse, multiply disadvantaged higher-weight patients themselves are needed. The purpose of this study was to use an intersectional approach to present recommendations for improving health care from an exploratory study among rural women of low income and higher weight.

\section{METHODS Design}

Methods used for this work have been reported ${ }^{41}$ and are briefly summarized herein. The study was designed with an interpretative phenomenological approach, ${ }^{43}$ which allows researchers to develop an interpretation of participants' lived experiences and meanings of events. The research project was approved by the Central Michigan University's institutional review board.

\section{Data Collection}

In-depth, face-to-face, semi-structured interviews were conducted from September 2017 to January 2018. The interviews focused on 3 main topics: 1) the ways weight stigma did or did not manifest in this sample and the effects of those experiences; 2) recommendations for improved health care and programming; and 3) beliefs about intergenerational body size. Given the abundance of data, these topics formed the basis for distinct analyses. Interview questions pertaining to participant recommendations are summarized in Table 1. The interviewer took detailed field notes during the interview process focusing on interaction, emotional and visual cues, and the interview setting. ${ }^{44}$ Interviews took place in a public location of participants' choosing and were professionally transcribed verbatim. Interviews lasted an average of 46 minutes (range: 20-84 minutes). Participants were provided a $\$ 50$ honorarium for their participation in the study.

Participants were 25 self-identified women, over 18 years of age, who had ever had a BMI of 30 or higher, could speak and understand English, were living in rural Michigan as defined by the U.S. Census Bureau urban-rural classification system, ${ }^{45}$ and had incomes less than twice the poverty guidelines set forth by the U.S. Department of Health and Human Services or qualified for an incomebased social assistance program. Participants were recruited through snowball sampling with community groups and organizations serving low-income families
Table 1. Interview Guide (Participant Recommendations)

\begin{tabular}{l|l}
\hline Interview questions & Probes \\
\hline $\begin{array}{l}\text { How do you think health } \\
\text { care providers treat } \\
\text { people of higher weights? }\end{array}$ & $\begin{array}{l}\text { In what ways do you think } \\
\text { health care providers have } \\
\text { treated you positively or } \\
\text { negatively? How do you think } \\
\text { those experiences are related } \\
\text { (or not related) to your size? }\end{array}$ \\
\hline $\begin{array}{l}\text { How do you think } \\
\text { experiences of being } \\
\text { judged (or not judged) } \\
\text { for size affect (or not } \\
\text { affect) people's health? } \\
\text { Lifestyles? Willingness to } \\
\text { see health care providers? }\end{array}$ & $\begin{array}{l}\text { How do you think experiences } \\
\text { of being judged (or not } \\
\text { (or not affected) your health? }\end{array}$ \\
Lifestyle? Willingness to see \\
$\begin{array}{l}\text { What do you recommend providers? } \\
\text { for improving women's } \\
\text { health? }\end{array}$
\end{tabular}

(eg, community centers, college campuses, food pantries, clinics), as well as through listservs and flyers. Participant characteristics are summarized in Table 2. Pseudonyms were assigned to those quoted, with one exception who indicated a specific preference.

\section{Analysis}

Analysis followed interpretative phenomenological approach procedures. ${ }^{43}$ Initial interview transcripts were repeatedly re-read, and annotations were made identifying recurring terms and concepts (hand-coding). A codebook was constructed of these meaning units. The codebook and interviews were uploaded into NVivo 11 software. Interviews were then coded line by line. The codebook was updated with new relevant codes as interviews proceeded and was also informed by previous literature in weight stigma. As analysis proceeded, similar codes were collapsed into broad, repeating patterns (themes).

Three coders initially analyzed interviews for themes pertaining to participants' experiences of treatment as higher-weight, rural, low-income women and the effects of such treatment, as reported previously. ${ }^{41}$ Following this initial analysis, the first author followed the established procedures, looking specifically at health care recommendations made by participants - as this was an area explicitly and discretely explored by the interviewer and preliminary analysis produced themes independent of participants' experiences with weight stigma and its effects.

\section{RESULTS}

Findings

Participants' recommendations for health care can be captured by two themes: holistic care and build rapport. 
Table 2. Study Participant ( $n=24)$ Demographics*

\begin{tabular}{|c|c|}
\hline Characteristics & n (\%) \\
\hline \multicolumn{2}{|l|}{ Gender } \\
\hline Female & $24(100)$ \\
\hline \multicolumn{2}{|l|}{ Age group } \\
\hline $20-25$ years & $3(12.5)$ \\
\hline $26-35$ years & $8(33.3)$ \\
\hline $36-45$ years & $3(12.5)$ \\
\hline $46-55$ years & $2(8.3)$ \\
\hline $56-65$ years & $4(16.7)$ \\
\hline $66-75$ years & $2(8.3)$ \\
\hline $76+$ years & $2(8.3)$ \\
\hline \multicolumn{2}{|l|}{ Employment status } \\
\hline Retired & $6(25)$ \\
\hline $\begin{array}{l}\text { Semi-retired/Working part-time in labor } \\
\text { force }\end{array}$ & $4(16.7)$ \\
\hline Working full-time in labor force & $3(12.5)$ \\
\hline Not working in labor force & $11(45.8)$ \\
\hline \multicolumn{2}{|l|}{ Education } \\
\hline Primary school & $2(8.3)$ \\
\hline Some secondary school & $2(8.3)$ \\
\hline Completed secondary school & $5(20.8)$ \\
\hline $\begin{array}{l}\text { Some/Completed trade/technical school } \\
\text { or college }\end{array}$ & $5(20.8)$ \\
\hline Some university & $5(20.8)$ \\
\hline $\begin{array}{l}\text { Completed university degree/Some } \\
\text { graduate education }\end{array}$ & $5(20.8)$ \\
\hline \multicolumn{2}{|l|}{ Race/Ethnicity } \\
\hline Black & $2(8.3)$ \\
\hline White & $20(83.3)$ \\
\hline Other & $2(8.3)$ \\
\hline \multicolumn{2}{|l|}{ Self-rated health } \\
\hline Good to very good & $13(54.2)$ \\
\hline Fair to poor & $11(45.8)$ \\
\hline
\end{tabular}

*Demographic data were unavailable for one participant.

These themes and their related subthemes are described hereinafter. Illustrative quotes by participants are presented in Table 3.

\section{Holistic Care}

Understand the Patient and Their Situation. Participants described the importance of HCPs getting to know patients personally and attempting to understand their experiences as members of a disadvantaged group, stressing the importance of identifying and considering social factors preventing these women from seeking or receiving adequate care. Sophia urged HCPs to acknowledge that many women adopt a caretaker role in which their health and safety are taken care of only after that of others, stating: "Start paying attention. Women don't take care of themselves. They're taking care of families."

Many participants also emphasized the importance of patient-specific care, expressing the desire that HCPs consider their values and circumstances and provide specialized treatments for their individual health needs. Naomi suggested that getting to know patients more personally could help HCPs improve their understanding of patients' health care needs: "But I think that, you know, if you interact with somebody and see how they are as a human being and then provide your services to cater to the specific health needs and specific mental needs of that patient, they might be, it, it might work out a lot better."

Participants explained that patient-specific care should involve HCPs considering their patient's medical and social history, what has and has not worked for them in the past, how comorbid health conditions affect one another, and how these factors could impact the effectiveness of potential treatments physically, psychologically, or operating within another dimension of health.

Offer Options and Supplemental Information. Many participants felt that their HCPs overly focused on weight and weight loss, without giving enough options or specific recommendations to treat their health issues nor adequate information to make an informed decision. Rather, they received vague references to healthy eating and exercise. Participants felt they had limited options either seeking alternative care, trying to treat themselves, or engaging in ongoing cycles of weight loss or dieting. Additionally, some participants noted HCPs dispense information and recommendations that do not take into account patients' individual social needs, such as income, leaving them unable to follow through with recommended care. Feedback from Kit captured this feeling: "I've had my thyroids checked, they've done everything possible. It's just, again, the health profession ... I mean, you're poor, you just can't afford it. ... If there was a program that I could get into, I would definitely try."

To address these issues, Joelle suggested that HCPs better educate patients: "[Give us] packets of information on, like, this is what you should eat, this is how you make these meals, this is where you should go to shop, this is your local grocery store near you, this is what they provide, in depth."

Likewise, Naomi recommended what she believed could be an effective, income-sensitive treatment method: "Instead of having to pay for a gym, offer free gym memberships to women who are obese, through the doctor's offices or, you know, through insurance." 
Table 3. Quotes That Capture Major Recommendations

\begin{tabular}{|c|c|}
\hline Theme & Quote(s) \\
\hline $\begin{array}{l}\text { Understanding patients and } \\
\text { their situations }\end{array}$ & $\begin{array}{l}\text { "Learn about your problems, your feelings, how you feel. I think if somebody would sit down } \\
\text { and take time to talk to you instead of having you come into the doctor's office and just push } \\
\text { you out in } 15 \text { minutes, the doctors and health professionals are not taking time to understand } \\
\text { how people in general feel." (Tamara) } \\
\text { "They need to listen better and understand before they go assuming that it's because you're } \\
\text { obese or it's because you're diabetic, or it's because, you know, you just are being lazy or, } \\
\text { just, whatever they think." (Patricia) }\end{array}$ \\
\hline $\begin{array}{l}\text { Offer options and } \\
\text { supplemental information }\end{array}$ & $\begin{array}{l}\text { "My doctor did take a lot of steps before even handing out those kinds of things. He did a lot } \\
\text { of different testing, and a lot of different nutrition doctors, and talking and different things. ... } \\
\text { They were trying to be very personable about it and ask me what my comfort is ... and what } \\
\text { we could do to make me feel better about it and how we could do different steps without } \\
\text { having to go down a medical road or if I felt I needed to go down a medical road after so long } \\
\text { of trying the other way." (Pam) } \\
\text { "... there isn't too many, a lot of, doctors that'll, like, do a study and take you as an individual } \\
\text { and say, 'Okay, let's test this, this, this; let's try this, this,' you know?" (Bette) } \\
\text { "Having a doctor back you up and realize, 'Okay, this health condition does this, this one } \\
\text { does this. Yes, change your meds and make things better.'... And, that I've had the good } \\
\text { experience because this doctor, he keeps me going." (Sandra) }\end{array}$ \\
\hline ffectively & $\begin{array}{l}\text { "I think it's all in how it's presented. It's how the health worker clicks with ... how they work } \\
\text { and how they click with each other. ... But it's all in how it's presented ... because if a person } \\
\text { is being fed information ... and it's being, like, rammed down my throat, it doesn't work. But if } \\
\text {... the same information is presented in a way that I know I have to, but it's not being forced } \\
\text { upon me, then it works." (Stacy) } \\
\text { "Well, they word things where I can understand 'em ... which is great. ... They ... look back } \\
\text { through your charts, they check and see what was wrong the last time." (Sophia) }\end{array}$ \\
\hline Take your time & $\begin{array}{l}\text { "... that kind of a friend-to-friend kind of thing, it would be very, very effective. But, doctors } \\
\text { and nurse practitioners usually are limited to about } 10 \text { minutes with each person." (Lucy) }\end{array}$ \\
\hline Have a positive attitude & $\begin{array}{l}\text { "They'd probably have to get rid of ... the negative view on people that are overweight." (Taylor) } \\
\text { "I feel like in ... health care settings ... people automatically assume that you are unhealthy } \\
\text { when they look at you ... it's more judgment. I feel like ... if a doctor's telling you what you need } \\
\text { to do ... it's more judgment than them telling someone who is healthier ... what they need to be } \\
\text { doing." (Lacy) }\end{array}$ \\
\hline
\end{tabular}

However, some participants expressed frustration with such recommendations in the context of their rural communities, which often lacked grocery stores and fitness facilities. Participants explained that the cost of driving or taking public transit to the nearest grocery store (which was often many miles away) was prohibitive, leaving them reliant on local options, such as dollar stores, which did not offer fresh food. For other participants without consistent access to vehicles, transit trips to the nearest grocery store could take up to a full day, an amount of time they simply could not afford to spare. Indeed, limited time, often due to employment and/or familial constraints, appears to be an important dimension to the barriers that low-income rural women face, particularly for those working multiple jobs to make ends meet. Rogue explained: "[Diet and exercise] helps somewhat ... when you have time for it. You gotta go to work and do your job. And you come home, take care of your family and stuff, and you're tired."

Ultimately, participants were frustrated by the seeming futility of HCPs' recommended weight-loss treatments. If HCPs continue suggesting diet and exercise, participants recommended that they provide more directive, in-depth, and practical information that acknowledge the interplay of lifestyle factors with physical health and the limitations associated with a rural, low-income context.

\section{Build Rapport}

Participants highlighted poor rapport as a roadblock to accessing satisfactory care, with lack of effective communication, lack of time, and poor attitude as primary contributors. 
Communicate Effectively. Participants wanted their HCPs to communicate information about health conditions and treatments in ways that they could understand and that gave them a sense of agency. Lucy illuminated this when she recalled a positive experience with her HCP that was counter to other participants" experiences: "We would just talk about everything that happened and what I thought was going to, and then she would, you know, prescribe the tests, or she would ... bring up things that I should be looking up and doing."

Lucy explained that having her HCP prioritize listening to her concerns and offering detailed explanations comforted her and allowed her to focus on improving her health. Many participants touched on this concept, expressing similar positive benefits of such an approach or indicating preference for it.

Take Your Time. Some participants attributed the lack of effective communication to time restrictions during consultations with HCPs. Pam described how time pressure can make patients feel their HCPs are not adequately listening to or caring for them: "[HCPS] need to space out those appointments and make them a little longer so they're not, 'Okay ... so here's your medicine, here's your prescription, whatever, goodbye." Participants felt they could not adequately communicate health issues or connect with their $\mathrm{HCPs}$, affecting patient-provider rapport-building and the overall quality of care received.

Have a Positive Attitude. Finally, many women cited HCPs' attitudes toward patients of higher weight as a substantial barrier to good rapport. Some participants had particularly negative experiences that they characterized as "almost traumatic," where HCPs described their bodies as burdensome to others. These experiences could have a pronounced impact on patients' perceptions of health care and willingness to seek care in the future due to fear or frustration with being belittled or insulted. Kit summarized: "When it comes to doctors and stuff, I just think that they need to treat people better, no matter which way you look at it."

Despite the generally negative experiences of participants, some spoke of predominantly positive experiences where they felt little to no stigma or discrimination. This held true for participants even when their HCPs continued to mention weight, as long as weight was not being "pushed." Most of these experiences were characterized by HCPs having an open, cooperative, and nonjudgmental approach while displaying genuine interest in the patient's experiences and health. Stacy expressed this: "He [her HCP] didn't make me feel like I was stupid or ... worthless or less than dirt, you know? ... 'That happened, you're overweight ... what are we going to do about it?' Not, 'What are you going to do about it?' 'What are we going to do about it?'",

Likewise, Lucy contrasted negative and positive experiences with different HCPs: "I've had doctors say to me, well, you're obese. Well, I have a mirror, I'm sure I know I am. ... But, I've had others say, okay, this is temporary, we'll be able to ... get some of the weight off you. That being the case ... I have to listen to the ones that say, we'll be able to do this."

Lucy's example highlights the impact that HCP attitudes can have on patients' feelings and willingness to continue care. By framing patients' situations and treatment options in a positive light, HCPs may help patients develop confidence in their HCP's ability to administer adequate care and in their personal ability to improve their health with continuing care.

\section{DISCUSSION}

This study examined the health care experiences of 25 Midwestern American higher-weight women from low-income, rural backgrounds and presents their recommendations for improvement. Results revealed that participants experienced high levels of weight stigma and unsatisfactory patient-provider relationships and expressed a desire for a more holistic approach to health care. Participants recommended that HCPs 1) understand patients and their situations, 2) provide options and supplemental information, 3) communicate effectively, 4) take time, and 5) have a positive attitude. Although these recommendations capture the unique experiences of women at the intersection of multiple disadvantaged groups, many of their recommendations align with previous findings regarding patient complaints about health care (Table 4). A recent review found patient complaints largely centered on the quality and safety of care, institutional issues, timing and access, communication, humaneness/caring, and patient rights - with $29.1 \%$ of all patient complaints focusing on the patient-provider relationship. ${ }^{46}$

Batsis and colleagues found that among higher-weight, higher-socioeconomic status, older-adult, rural Americans there was a particularly negative association with the term "obesity." " Similar to participants in the present study, these patients reported experiences of stigmatization and shame. Physicians likewise expressed difficulties in documenting patients' weight sensitively and were resistant to labeling "obesity" a disease. However, patients did express concern about health and fitness. Therefore, what may be most effective for this population is to focus more on immediate, patient-identified wellness concerns rather than weight or 
Table 4. Summary of Recommendations From Participants and Related Literature

\begin{tabular}{|c|c|}
\hline Themes & Description \\
\hline $\begin{array}{l}\text { Understanding } \\
\text { their situations }\end{array}$ & $\begin{array}{l}\text { - Attempt to understand patients' experience as low-income, rural women of higher weight by } \\
\text { inquiring about their lives } \\
\text { - Consider patients' psychological and social circumstances as they relate to their physical } \\
\text { health when assessing patients by considering psychosocial, internalized stigmas and } \\
\text { structural stressors they may encounter } \\
\text { - Tailor treatments and recommendations to the individual needs of each patient }\end{array}$ \\
\hline $\begin{array}{l}\text { Offer options and } \\
\text { supplemental information }\end{array}$ & $\begin{array}{l}\text { - Provide treatment options alternative to diet and exercise and ask patients about } \\
\text { preexisting routines } \\
\text { - If diet and exercise recommendations are to be made, ensure they are specific and } \\
\text { informative } \\
\text { - Provide affordable and accessible treatment options - such as considering where patients } \\
\text { can exercise/access affordable produce locally } \\
\text { - Incorporate interdisciplinary teams with social workers, psychologists, dieticians, and } \\
\text { exercise physiologists to address patients' multifaceted and highly specific concerns and } \\
\text { contexts } \\
\text { - Advocate for greater access to poverty reduction, mental health, and food security initiatives }\end{array}$ \\
\hline Communicate effectively & $\begin{array}{l}\text { - Speak in a manner that patients can understand (avoid medical jargon) } \\
\text { - Provide patients with direct, in-depth, and informative information regarding their health and } \\
\text { available treatment options } \\
\text { - Advocate for a greater focus on communication, weight stigma, and the social determinants } \\
\text { of health in medical education }\end{array}$ \\
\hline Take your time & $\begin{array}{l}\text { - Ensure consultations are long enough to collect a thorough patient history and to address } \\
\text { all concerns patients may have } \\
\text { - Advocate for greater health care accessibility and alterations to standard funding models to } \\
\text { incentivize longer standard appointment visits }\end{array}$ \\
\hline Have a positive attitude & $\begin{array}{l}\text { - Avoid endorsing common anti-fat biases (eg, laziness, poor diet and exercise, nonadherence) } \\
\text { - Provide open, empathetic, and nonjudgmental care } \\
\text { - Consider each patient's individual starting point and celebrate small victories }\end{array}$ \\
\hline
\end{tabular}

"obesity," per se. This also may help alleviate some of the frustration experienced by physicians in managing higherweight patients. ${ }^{37}$ Seeking to ameliorate the effects of stigma may be especially pertinent for patients living on a reduced income, as they may encounter socioeconomic barriers in accessing alternative HCPs.

Participants' emphasis on positive communication, acknowledgment and resource provision as important barriers aligns with some reports of HCP perspectives. Australian primary care physicians discussed multiple barriers that effect their patients' diet and exercise options. ${ }^{37}$ Dieticians in Canada similarly expressed that patients, particularly rural patients and lowincome patients, may encounter access issues with respect to health care and healthy lifestyles. ${ }^{48}$ These dieticians highlighted the importance of consistency in messaging among HCPs and stressing small, positive achievements. Koball and colleagues' mixed-method study on American patients who recently saw an internal medical provider noted that the majority of patients of all weights appreciate specific advice and recommendations concerning managing weight through lifestyle changes (diet and exercise). ${ }^{49}$ However, patients with a higher BMI desired more sensitivity when discussing the topic (as opposed to complete avoidance of weight as a topic or very direct speech about weight). Importantly, the barriers mentioned by participants in the present study and those mentioned by HCPs in previous research extend beyond individual patient encounters to the redressing of structural inequities. ${ }^{48}$

There is often an underlying assumption that individuals have access to discretionary time and affordable food and that the only barriers that individuals encounter are easily overcome on an individual, and even internal, level. ${ }^{50}$ Higher income also may have a protective effect on the mental health effects of experiencing weight 
discrimination among women. ${ }^{51}$ Therefore, being cognizant of the particular vulnerability of lower-income, higher-weight women to weight stigma and reductionist assumptions of lifestyle "choices" may be essential in offering sensitive care.

Participants were further frustrated by the vague, overstated, and often futile recommendation of improving diet and exercise. Similar to other studies, participants stated that if diet and exercise were a concern, their preference was for specific plans, goals, and recommendations. ${ }^{52,53}$ Although participants described positive components of rural life, such as growing one's own food, they also described issues with transportation, food access, and employment - echoing other studies. ${ }^{17,54}$ Information transmitted to individuals that fails to account for disadvantaging circumstances is unlikely to prove valuable, discounts individuals' experiential knowledge, and can reinforce the view that the disadvantaged are merely ignorant. ${ }^{55-57}$ Health advice must be contextualized within participants' broader life experiences and challenges.

While better patient-provider communication is associated with improved health outcomes, ${ }^{58}$ quality patientprovider communication appeared to be lacking for many participants. Some described experiences in which their HCP did not appear knowledgeable or comfortable discussing issues surrounding weight or did not speak in a way that the participant understood. Other participants felt that their HCPs spent too much time on weight and expressed frustration with receiving vague, patronizing recommendations about weight management based on inaccurate assumptions concerning the participants' lifestyles and social circumstances. These findings correspond with studies done from the HCPs' standpoint, which indicate HCPs do not receive enough training on weight management and communication. ${ }^{36}$ Koball and colleagues noted that patients want their HCPs to be straightforward and honest in their conversations about their weight; ${ }^{49}$ however, women with high BMI wanted HCPs to be sensitive about the topic and called for HCPs to be more aware of their life circumstances. Overall, previous research on women's experiences in health care indicates that weight is not something that should be ignored and that women are aware of their bodies. However, acknowledging that weight is only part of the whole health of a person, and not the defining quality, can move health care to a more satisfying and patientcentered model.

These findings are strongly juxtaposed to studies that have measured HCPs' comfort with discussing weight with patients, noting that many HCPs do not feel like they have the knowledge, time, or confidence to have these discussions. ${ }^{36,37}$ Thus, one barrier to quality patientprovider communication could be time, as patientprovider consultations are often restricted to short durations, a limitation that particularly affects the multiply disadvantaged..$^{59}$ More time for the consultation may have allowed for HCPs to learn about participants' contexts and concerns, rather than relying on assumptions that may reflect weight stigma. ${ }^{41,60}$ Indeed, participants in the present study expressed a desire for longer consultations and stronger relationships with their HCPs to develop more effective health plans that take their circumstances into account.

Finally, the most commonly cited barrier to effective communication and access to safe and satisfactory care was poor HCP attitudes toward patients of higher weights. Almost all participants reported experiencing some form of weight stigma or discrimination while seeking care. Common examples within the current study include participants' feelings that HCPs believe that higher-weight patients are lazy, lack willpower, have poor diet and exercise regimens, and that all higher-weight patients' health conditions are due to weight. Participants suggested that HCPs increase their effort to treat patients respectfully and that getting to know patients personally and exploring potential causes of illness independent from weight could improve the quality of care received.

Unfortunately, no specific strategy for reducing weight stigma among health care professionals has been shown to be consistently effective. ${ }^{61}$ One challenge in reducing weight stigma is that it is often implicit - HCPs may not even be aware they hold these attitudes. ${ }^{62}$ Furthermore, as members of society, HCPs are inundated with weightstigmatizing messages in multiple venues. ${ }^{61}$ Weight stigma intervention research focusing on developing skills and competencies among HCPs, with long-term follow-up, should be prioritized. ${ }^{61}$ The similarity of our findings to other studies suggests that higher weight may indeed operate as a "master status" and come to dominate an HCP's view of a patient and that patient's experience in the health care encounter. ${ }^{5-8}$ As such, adopting a weight-inclusive approach, which aims to improve patients' health independent from weight loss, may be one promising strategy for addressing these participants' recommendations. $^{5}$ If weight inclusivity is practiced more broadly and incorporated into medical training, it may ultimately shift the normative assumption that higher-weight individuals are necessarily unhealthy and irresponsible, which feeds into their negative experiences in the health care system and stigmatization. ${ }^{60}$ More weight-inclusive policies, shifting focus from weight 
to holistic well-being, recognizing patients' unique circumstances, and giving space for higher-weight people to guide policies can improve health care without contributing to stigmatization. ${ }^{5,35}$

\section{Limitations}

The study sample was intentionally homogenous and took as its focus a very particular population; however, further research should be undertaken on the experiences of higher-weight, rural, and low-income men, and weight stigma research should expand in terms of diversity of samples and incorporation of intersecting forms of marginalization. ${ }^{4}$ For example, in addition to the intended sample characteristics, the present sample was mostly White and quite well educated. More research should be conducted with racialized persons on experiences of weight stigma and those with lower educational attainment. Rapport may have been affected by the interviewer's slim body size and differential socioeconomic status; however, field notes generally suggest study rapport was established with participants wanting to provide helpful data to a student. The study design and small sample size precludes generalization but allows for a more in-depth analysis. Furthermore, the congruence of the findings to other studies suggests themes may be transferable to other populations.

\section{CONCLUSIONS}

This study identifies barriers faced by low-income, ruralresiding women when accessing health care and suggests potential improvements in care delivery. Participants recommended more holistic care and improved patientprovider relationships, with an emphasis on patientcentered communication and poor HCP attitudes. To ensure patients receive holistic care, participants suggested that HCPs take time to understand patients and their situation more intimately. This includes identifying patients' goals and preferences regarding treatment and understanding how patients' income and rural status may influence their ability to access and follow through with care plans. Participants also recommended that HCPs tailor treatments to the specific needs of patients, including considering alternative treatments to diet and exercise and providing more in-depth information to patients.

Future research should explore how implicit and explicit weight stigma can be reduced within health care. As this study focused solely on female-identifying participants, and the sample was largely well-educated and White, weight stigma research on male-identifying participants, those encountering racial bias, and those with lower education is encouraged.

\section{Patient-Friendly Recap}

-Women are disproportionately stigmatized based on their weight or appearance, and health disparities are often found in rural, low-income patient populations.

- The authors interviewed women from rural, lowincome backgrounds who self-identified as having higher weight about their experiences with health care providers.

- Patient recommendations for providers focused on correcting physician biases, building better rapport, and providing holistic care.

- Findings may inform future communication and training approaches aimed at eliminating weight stigma in health care.

\section{Acknowledgments}

The authors are grateful to participants for their involvement and to Jackson Bensley for references.

\section{Author Contributions}

Study design: Bombak. Data acquisition or analysis: Watson, Hughes, Robinson, Bombak. Manuscript drafting: all authors. Critical revision: Robinson, Billette, Bombak.

\section{Conflicts of Interest}

None.

\section{Funding Sources}

Funding was provided by a Central Michigan University Early Career Grant awarded to Andrea Bombak.

\section{References}

1. Puhl RM, Moss-Racusin CA, Schwartz MB, Brownell KD. Weight stigmatization and bias reduction: perspectives of overweight and obese adults. Health Educ Res. 2008;23:347-58. CrossRef

2. Puhl RM, Andreyeva T, Brownell KD. Perceptions of weight discrimination: prevalence and comparison to race and gender discrimination in America. Int J Obes (Lond.). 2008;32:9921000. CrossRef

3. Gard M, Wright J. The Obesity Epidemic: Science, Morality, and Ideology. Routledge; 2005.

4. Himmelstein MS, Puhl RM, Quinn DM. Intersectionality: an understudied framework for addressing weight stigma. $\mathrm{Am} \mathrm{J}$ Prev Med. 2017;53:421-31. CrossRef

5. Tylka TL, Annunziato RA, Burgard B, et al. The weightinclusive vs. weight-normative approach to health: evaluating the evidence for prioritizing well-being over weight loss. J Obes. 2014;2014:983495. CrossRef

6. Goffman E. Stigma: Notes on the Management of Spoiled Identity. Prentice-Hall; 1963. 
7. Phelan SM, Burgess DJ, Yeazel MW, Hellerstedt WL, Griffin JM, van Ryn M. Impact of weight bias and stigma on quality of care and outcomes for patients with obesity. Obes Rev. 2015;16:319-26. CrossRef

8. Carr D, Friedman MA. Is obesity stigmatizing? Body weight, perceived discrimination, and psychological well-being in the United States. J Health Soc Behav. 2005;46:244-59. CrossRef

9. Bombak AE. The contribution of applied social services to obesity stigma-related public health approaches. $J$ Obes. 2014;2014:267286. CrossRef

10. Schwartz MB, Chambliss HO, Brownell KD, Blair SN, Billington C. Weight bias among health professionals specializing in obesity. Obes Res. 2003;11:1033-9. CrossRef

11. Bacon L, Aphramor L. Weight science: evaluating the evidence for a paradigm shift. Nutr J. 2011;10:9. CrossRef

12. Hebl MR, Xu J. Weighing the care: physicians' reactions to the size of a patient. Int $J$ Obes Relat Metab Disord. 2001;25:1246-52. CrossRef

13. Myers A, Rosen JC. Obesity stigmatization and coping: relation to mental health symptoms, body image, and self-esteem. Int J Obes Relat Metab Disord. 1999;23:221-30. CrossRef

14. Alegria Drury CA, Louis M. Exploring the association between body weight, stigma of obesity, and health care avoidance. J Am Acad Nurse Pract. 2002;14:554-61. CrossRef

15. Mensinger JL, Tylka TL, Calamari ME. Mechanisms underlying weight status and healthcare avoidance in women: a study of weight stigma, body-related shame and guilt, and healthcare stress. Body Image. 2018;25:139-47. CrossRef

16. Kasten G. Listen... and speak: a discussion of weight bias, its intersections with homophobia, racism, and misogyny, and their impacts on health. Can J Diet Pract Res. 2018;79:133-8. CrossRef

17. Harris JK, Beatty K, Leider JP, Knudson A, Anderson BL, Meit M. The double disparity facing rural local health departments. Annu Rev Public Health. 2016;37:167-84. CrossRef

18. Davidsson N, Södergård B. Access to healthcare among people with physical disabilities in rural Louisiana. Soc Work Public Health. 2016;31:188-95. CrossRef

19. Haynie DL, Gorman BK. A gendered context of opportunity: determinants of poverty across urban and rural labor markets. Sociol Q. 1999;40:177-97. CrossRef

20. Bennett KJ, Dismuke CE. Families at financial risk due to high ratio of out-of-pocket health care expenditures to total income. J Health Care Poor Underserved. 2010;21:691-703. CrossRef

21. Colls R, Evans B. Making space for fat bodies? A critical account of 'the obesogenic environment'. Prog Hum Geogr. 2014;38:733-53. CrossRef

22. Schuster RC, Han SY, Brewis AA, Wutich A. Increasing overweight and obesity erodes engagement in one's neighborhood by women, but not men. Prev Med Rep. 2018;10:144-9. CrossRef

23. Lent MR, Napolitano MA, Wood GC, et al. Internalized weight bias in weight-loss surgery patients: psychosocial correlates and weight loss outcomes. Obes Surg. 2014;24:2195-9. CrossRef

24. Darling R, Atav AS. Attitudes toward obese people: a comparative study of nursing, education, and social work students. J Prof Nurs. 2019;35:138-46. CrossRef

25. McPhail D, Chapman GE, Beagan BL. The rural and the rotund? A critical interpretation of food deserts and rural adolescent obesity in the Canadian context. Health Place. 2013;22:132-9. 다요
26. Gessert C, Waring S, Bailey-Davis L, Conway P, Roberts M, VanWormer J. Rural definition of health: a systematic literature review. BMC Public Health. 2015;15:378. CrossRef

27. Goins RT, Spencer SM, Williams K. Lay meanings of health among rural older adults in Appalachia. J Rural Health. 2011;27(1):13-20. CrossRef

28. Liu JJ, Bellamy G, Barnet B, Weng S. Bypass of local primary care in rural counties: effect of patient and community characteristics. Ann Fam Med. 2008;6:124-30. CrossRef

29. McCulloch BJ, Jackson MNG, Lassig SL. Worry and bother: factors in rural women's health decision making. $J$ Women Aging. 2015;27:251-65. CrossRef

30. Simmons LA, Anderson EA, Braun B. Health needs and health care utilization among rural, low-income women. Women Health. 2008;47:53-69. CrossRef

31. Bernard M, Fankhänel T, Riedel-Heller SG, Luck-Sikorski C. Does weight-related stigmatisation and discrimination depend on educational attainment and level of income? A systematic review. BMJ Open. 2019;9(11):e027673. CrossRef

32. Balkhi AM, Parent MC, Mayor M. Impact of perceived weight discrimination on patient satisfaction and physician trust. Fat Studies. 2013;2:45-55. CrossRef

33. Mason C, Foster-Schubert KE, Imayama I, et al. History of weight cycling does not impede future weight loss or metabolic improvements in postmenopausal women. Metabolism. 2013;62:127-36. CrossRef

34. Mason K. The unequal weight of discrimination: gender, body size, and income inequality. Soc Probl. 2012;59:411-35. https://www.jstor.org/stable/10.1525/sp.2012.59.3.411

35. Hunger JM, Smith JP, Tomiyama AJ. An evidence-based rationale for adopting weight-inclusive health policy. Soc Issues Policy Rev. 2020;14:73-107. CrossRef

36. Lewis KH, Gudzune KA. Overcoming challenges to obesity counseling: suggestions for the primary care provider. $J$ Clin Outcomes Manag. 2014;21(3):123-33.

37. Ashman F, Sturgiss E, Haesler E. Exploring self-efficacy in Australian general practitioners managing patient obesity: a qualitative survey study. Int $J$ Family Med. 2016;2016:8212837. CrossRef

38. Cravens JD, Pratt KJ, Palmer E, Aamar R. Marriage and family therapy students' views on including weight bias training into their clinical programs. Contemp Fam Ther. 2016;38:210-22. CrossRef

39. Puhl RM, Phelan SM, Nadglowski J, Kyle TK. Overcoming weight bias in the management of patients with diabetes and obesity. Clin Diabetes. 2016;34:44-50. CrossRef

40. Crenshaw K. Demarginalizing the intersection of race and sex: a black feminist critique of antidiscrimination doctrine, feminist theory and antiracist politics. Univ Chic Leg Forum. 1989;(1):8. CrossRef

41. Hughes K, Bombak A, Ankomah S. Experiences of weightrelated stigma among low income rural women of higher weights from the Midwestern United States. Qual Res Med Healthc. 2019;3(1):25-31. CrossRef

42. Grollman EA. Multiple disadvantaged statuses and health: the role of multiple forms of discrimination. J Health Soc Behav. 2014;55:3-19. CrossRef

43. Smith JA, Osborn M. Interpretative phenomenological analysis. In: Smith JA (ed). Qualitative Psychology: A Practical Guide to Research Methods, Second Edition. Sage Publications; 2008, pp. 53-80. 
44. Emerson RM, Fretz RI, Shaw LL. Writing Ethnographic Fieldnotes, Second Edition. University of Chicago Press; 2011.

45. U.S. Census Bureau. Urban and rural. Page revised February 24, 2020; accessed November 12, 2020. https://www.census. gov/programs-surveys/geography/guidance/geo-areas/urbanrural.html

46. Reader TW, Gillespie A, Roberts J. Patient complaints in healthcare systems: a systematic review and coding taxonomy. BMJ Qual Saf. 2014;23:678-89. CrossRef

47. Batsis JA, Zagaria AB, Brooks E, et al. The use and meaning of the term obesity in rural older adults: a qualitative study. J Appl Gerontol. 2020 Feb 15;733464820903253. CrossRef

48. Aboueid S, Pouliot C, Nur T, Bourgeault I, Giroux I. Dietitians' perspectives on patient barriers and enablers to weight management: an application of the social-ecological model. Nutr Diet. 2019;76:353-62. CrossRef

49. Koball AM, Mueller PS, Craner J, et al. Crucial conversations about weight management with healthcare providers: patients' perspectives and experiences. Eat Weight Disord. 2018;23:87-94. $\underline{\text { CrossRef }}$

50. Lee JA, Pausé CJ. Stigma in practice: barriers to health for fat women. Front Psychol. 2016;7:2063. CrossRef

51. Ciciurkaite G, Perry BL. Body weight, perceived weight stigma and mental health among women at the intersection of race/ethnicity and socioeconomic status: insights from the modified labelling approach. Sociol Health Illn. 2018;40:18-37. $\underline{\text { CrossRef }}$

52. Potter MB, Vu JD, Croughan-Minihane M. Weight management: what patients want from their primary care physicians. J Fam Pract. 2001;50:513-8.

53. Brown I, Thompson J, Tod A, Jones G. Primary care support for tackling obesity: a qualitative study of the perceptions of obese patients. Br J Gen Pract. 2006;56:666-72.
54. Wong ST, Regan S. Patient perspective on primary health care in rural communities: effects of geography on access, continuity and efficiency. Rural Remote Health. 2009;9(1):1142.

55. Bowen S, Brenton J, Elliott S. Pressure Cooker: Why Home Cooking Won't Solve Our Problems and What We Can Do About It. Oxford University Press; 2019.

56. Warin M. Information is not knowledge: cooking and eating as skilled practice in Australian obesity education. Aust $J$ Anthropol. 2018;29:108-24. CrossRef

57. Warin M, Zivkovic T. Fatness, Obesity, and Disadvantage in the Australian Suburbs: Unpalatable Politics. Palgrave McMillan; 2019.

58. Stewart MA. Effective physician-patient communication and health outcomes: a review. CMAJ. 1995;152:1423-33.

59. Fiscella K, Epstein RM. So much to do, so little time: care for the socially disadvantaged and the 15-minute visit. Arch Intern Med. 2008;168:1843-52. CrossRef

60. Puhl RM, Heuer CA. Obesity stigma: important considerations for public health. Am J Public Health. 2010;100:1019-28. CrossRef

61. Alberga AS, Pickering BJ, Hayden KA, et al. Weight bias reduction in health professionals: a systematic review. Clin Obes. 2016;6:175-88. CrossRef

62. Chapman EN, Kaatz A, Carnes M. Physicians and implicit bias: how doctors may unwittingly perpetuate health care disparities. J Gen Intern Med. 2013;28:1504-10. $\underline{\text { CrossRef }}$

(C) 2021 Advocate Aurora Health, Inc. 